\title{
Management of Underground Infrastructure
}

\author{
Sachin Bajaj \\ Department of CS\&IT, \\ Dr. Babasaheb Ambedkar \\ Marathwada University, \\ Aurangabad-431003, \\ Maharashtra, India.
}

\author{
Amol Adhave \\ Department of CS\&IT, \\ Dr. Babasaheb Ambedkar \\ Marathwada University, \\ Aurangabad-431003, \\ Maharashtra, India.
}

\author{
Priyanka Avhad \\ Department of CS\&IT, \\ Dr. Babasaheb Ambedkar \\ Marathwada University, \\ Aurangabad-431003, \\ Maharashtra, India.
}

\begin{abstract}
India has announced a project of making 100 smart cities. For making a smart city one needs to consider many parameters such as smart water, smart electricity, smart transportation etc. There will be a need of smart underground infrastructure which includes underground water pipelines, communication cables, gas pipelines, electric flow, etc. As most of the cities in India have adopted underground drainage system, it is very important that this system should work in proper manner to keep the city clean, safe and healthy. If they fail to maintain the drainage system the pure water may get contaminated with drainage water and can spread infectious diseases. So different kind of work has been done to detect, maintain and manage these underground systems. Also Leaks and bursts are an unavoidable aspect of water distribution systems management, and can account for significant water loss within a distribution network if left undetected for long periods. This paper presents the implementation and design functions for monitoring and managing underground drainage system with different approaches. It also gives description about Waterwise system and detection method to detect leakage defects in sewer pipeline. Also some part of condition rating model for underground Infrastructure Sustainable Water Mains and Intelligent system for underground pipeline assessment, rehabilitation and management are explained.
\end{abstract}

\section{Keywords}

GPS, RFID Metal Detector, Sensor, WaterWise.

\section{INTRODUCTION}

Underground drainage system is important component of urban infrastructure. It is considered to be city's lifeline. Most management on underground drainage is manual therefore it is not efficient to have clean and working underground system. Therefore, it is essential to develop a system which can handle underground drainage without human intervention. Underground Drainage involves sewerage system, gas pipeline network, water pipeline and manholes. In this paper, different functions are described which are used for maintenance and monitoring underground drainage system.

Underground manhole is one of the most efficient solutions to drainage .However putting these manholes underground is very challenging. Also the difficulties derived from the fact that manhole is hard to search once it is hide under the road surface. Therefore, it is necessary to develop a set of mechanism which can be used to search, authenticate manhole in order to manage this problem. Closings of these manholes are covered by a manhole cover. Manhole cover is a flat plug which is designed to protect from unauthorized access. Also some people implements Underground Drainage and Manhole Monitoring System. This is a model which provides a system which is able to monitor the water level, atmospheric temperature. Also it can be used to find pressure inside a manhole and to check whether a manhole lid is open. Also this system can be used to monitors underground installed electric power lines. Manhole explosion is one of the most dangerous and serious problems as these explosions releases of chemical and electrical energy inside a manhole. Manhole explosion events can be of three types mainly smoking events, fires and explosion due to sudden raise in pressure so they can monitor these manholes using sensors. If such drainage system gets blocked and water overflows it can be identified by sensor system. Also if suppose that manhole lid is open it will immediately sense by the sensor in system, and that sensor sends information via transmitter which is located in that area to the corresponding managing station.

But sometime this fails to solve these kinds of problems because it increases the number of sensors. It is not able to provide scalability. The technology based on Automated Internet of Things for Underground Drainage and Manhole monitoring System (UDMS) for Metropolitan Cities overcomes all these problems.Leaks and bursts are the aspects which are challenging aspect to manage system efficiently. These are reasons for significant water loss. Therefore it is necessary to build a system which has the ability to detect and localize pipe burst and leaks. This paper describes the Water wise platform which focusing on capabilities to detect and localize bursts, identify hotspots, areas at risk of leaks and bursts in the network.

\section{Methodology}

\subsection{Search and identification of Manholes}

Underground manholes have threefold characteristic: Hidden: Manhole cover is hidden under the road pavement of the underground environment. Therefore some kind of scientific tools are required to search for the exact location. Metallic: Manholes are usually outfitted with or produced by metal materials. Identification: It is necessary to identify and locate position of desired manhole without mistake.Based on the characteristics of underground manholes, there are some feasible ways to identify and locate these manholes for its Maintenance.[1]Different methods are applied to search for the manholes hidden underground:

(1) Metal detector approach, (2) GPS positioning approach, and (3) RFID positioning approach.

Various kinds of methods can be applied to search manholes. Three methods are applied to search for the manholes hidden underground:

- Metal detection

- $\quad$ RFID authentication

- GPS location 


\subsection{Metal Detector Approach}

Metal detectors are used by people to discover buried treasures in past. Now a day, metal detectors are used by security agencies to identify a person wearing any type of metal. If the manhole cover is made of metal material, then it can be easily identified by metal detectors. A schematic diagram for metal detector is given in figure 1.Metal detectors work on the principle of electromagnetic induction. Metal detector contains coil which generate electromagnetic field around it. When metal detector moves over the metal objects then metal has induce current. This current is called Eddy current. Due to the formation of Eddy current metal generates its own magnetic field. Generated field is received by metal detector and using buzzer or LED. [2]

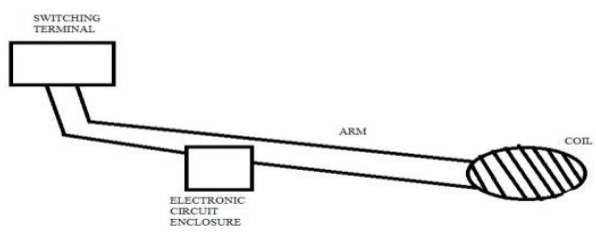

Figure 1-Handheld metal detector

Thus, Metal detectors can be used to search for the location of manholes, with two limitations: (1) Metal detector can only detect the metal object with very short distance.(2)Metal Detector cannot recognize details of metal.

\subsection{RFID Positioning Approach:}

The main application of RFID (Radio Frequency Identification) is the identity identification. RFID tags develop to replace barcode. But the advantages of RFID i.e. wireless identification make it useful in different field like vehicle identification, managing inventory, theft detection in malls. RFID is popular technology because no line of sight needed to detect and one more thing passive tag. Passive tags does not have power source and also store information other than tag.

A basic RFID system consists of three components:

- An antenna or coil

- A transceiver (with decoder)

- A transponder (RF tag) electronically programmed with unique information

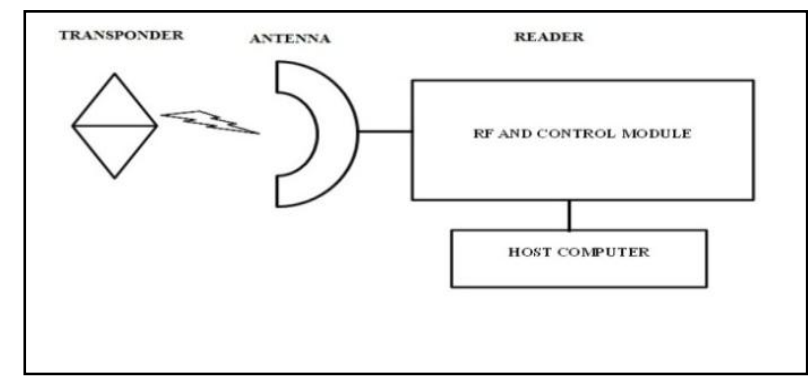

Figure 2-Working of RFID

The working of RFID is explained in figure 2 [3].A transponder consists of microchip and antenna. Transponder is passive which means does not have power source. It works on principle of induction when reader (transceiver) emits radio waves which are received by antenna of tag to power itself. Passive tags work in low range.

When transponder comes in range of radio frequency it start transmitting tag information [4].

Table 1-RFID operating frequencies

\begin{tabular}{|l|l|l|}
\hline Frequency range & Frequencies & $\begin{array}{l}\text { Passive Read } \\
\text { distance }\end{array}$ \\
\hline Low Frequency & $120-140 \mathrm{KHz}$ & $10-20 \mathrm{~cm}$ \\
\hline High Frequency & $13.56 \mathrm{MHz}$ & $10-20 \mathrm{~cm}$ \\
\hline $\begin{array}{l}\text { Ultra High } \\
\text { Frequency }\end{array}$ & $868-928 \mathrm{MHz}$ & 3 meters \\
\hline Microwave & $2.45 \& 5.8 \mathrm{GHz}$ & 3 meters \\
\hline Ultra Wide Band & $3.1-10.6 \mathrm{GHz}$ & 10 meters \\
\hline
\end{tabular}

Table 1 shows different operating frequencies of passive RFID tag. Among them microwave and Ultra wide band are not suitable for use as they are absorbed by water. Only high frequency is suitable for manhole tagging.

\subsection{GPS Positioning Approach}

The Global Positioning System consists of 29 satellites that circle the globe once every 12 hours, to provide worldwide position, time and velocity information. The principle of GPS positioning is to receive more than three GPS satellite signals together with the computation of triangulation to derive the coordinates of the GPS receivers. GPS can collect both the location and the data [5].Global positioning system uses 3 satellites to triangulate the position on earth. For the measure of height from earth surface, it uses 1 more satellite.

The GPS positioning is achieved by measuring time taken by signal to reach device. This time is considered as radius and the location of device anywhere on the sphere form by the radius. It's not easy to determine location using single satellite so to reduce search area $2^{\text {nd }}$ satellite is used which gives less area form by $1^{\text {st }}$ and $2^{\text {nd }}$ satellite. Still position cannot be specified then $3^{\text {rd }}$ satellite forms a sphere intersecting sphere formed by other 2 satellite which is the approximately correct location on earth. GPS divided in 3 segments (1) Space segment. (2) User segment. (3) Control segment. GPS tags helps to map the location of each manhole [6].

Manholes are searched by metal detector and RFID and then map their location using GPS device. This will help to form the information system of manhole on mapGPS has its own limitations (1) GPS accuracy up to $15 \mathrm{~m}$ (2) It can be affected by natural phenomenon.

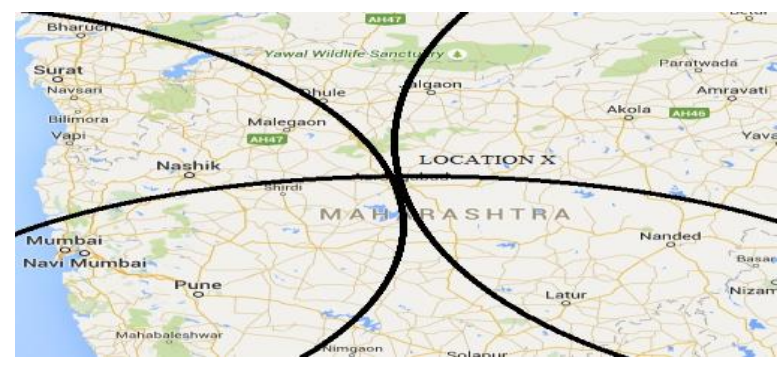

Figure 3 Trilateration works in three-dimensions to locate a fixed position on the earth, for height determination a fourth satellite (not shown in the figure) will be needed 


\section{Position Format}

The format for denoting Latitude and Longitude is adopted as: Degrees - Minutes - Seconds (hh dd mm' ss.s", N 43 - 40'55.8" E). The representation may be used for the underground infrastructure. GIS technology helps in management of underground assets. Currently most of the data is in the form of 2D. 2D representation does not provide real world idea so people are transforming $2 \mathrm{D}$ data into $3 \mathrm{D}$ data.3D data gives more clear view of underground infrastructure. For bringing 2D to 3D GIS, Augmented reality modeling language is used. One of research project called Vidente following the vision of registered 3D visualization of underground networks on handheld devices in real-time and another technique using GIS. GIS package support the 3D modeling and visualization [7].

Mobile GIS extends Geographic Information Systems beyond the office to the field by incorporating technologies such as mobile devices, wireless communication and positioningsystems. Current commercial mobile GIS products include, FieldWorker, GPSPilot, Fugawi,Todarmal, ESRI ArcPad, MapInfo, MapXmobile, Smallworld Field Information System or Map Frame Field Smart. Field Worker is used for exchanging information with mobile workers.GPSPilot and Fugawi are examples of traditional 2D maps intended for navigation. Todarmal provides the possibility to create map content (points, lines and 2D polygons) online in a layered manner. ESRI ArcPad is intended for managing point type GIS data, where digital photos can be attached to point information. The ArcPad comes with a support for routing with street map data.MapInfo Map Xmobile is a development tool similar to ArcPad, intended for creating map applications. Small world Field Information System and Map Frame Field Smart represent mobile GIS particularly aiming at needs of utilities.

\section{New methods for mobile GIS offered by VIDENTE}

The figure 4 gives the schematic diagram of handheld augmented reality device by Vidente.

It can be seen from the Figure, that it has four components, viz. GPS, Antenna, Camera, Joystick and Ultra mobile PC (UMPC).

Handheld augmented reality extends traditional 2D or 3D visualizations by overlaying registered visualizations over video footages [8].

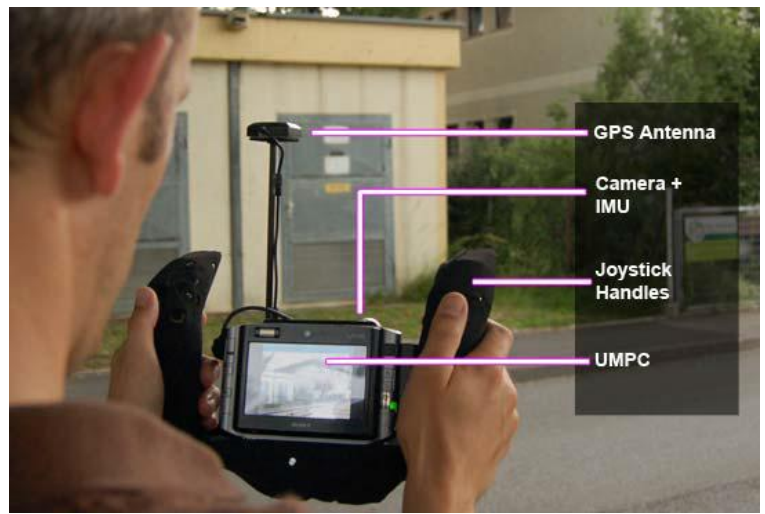

Figure 4-Vidente: handheld augmented reality device.

\section{Underground Drainage and Manhole Monitoring System}

Using remote monitoring system one can monitor the internal states of the manhole. The problems of underground drainage systems can be solved efficiently. Environmental change like rainy season is the main reason for such problems. Any kind of problem occurred in manhole is detected by sensors and sends this information to remote monitoring station Figure 5 shows the working transmitter and receiver in system. In which sensors senses all the parameters and converts it into electrical quantity. Receiver collects the serial data from the serial port and displayed it on the monitor using terminal emulator program [9].

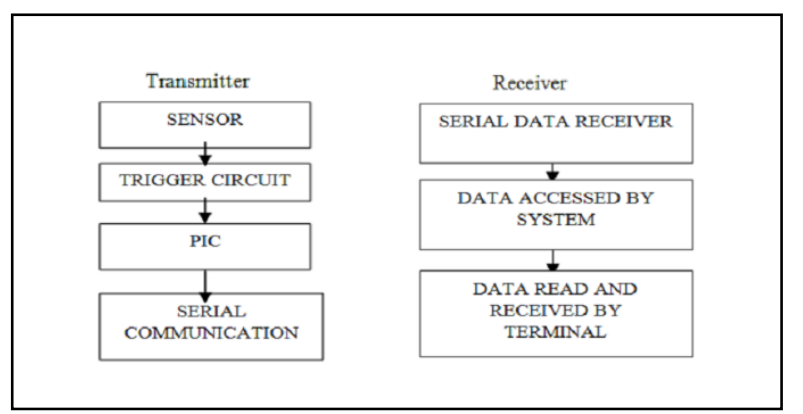

Figure 5- Flow diagram of transmitter and receiver to detect problems in manholes

\section{Sensors}

Sensors are used to detect the characteristics of changes in environment. It detects changes in characteristics and provides a corresponding output. Sensor can use here are Pressure sensor, temperature sensor, force sensor, chemical sensor, light sensor etc.

\section{Trigger circuit}

Trigger circuit is a multi vibrator circuit with stable states. Its output changes drastically in response to minimum change in its input.

\section{Programmable Interface Controller (PIC)}

PIC Stand for Programmable Interface Controllers. PIC Microcontroller can be programmed to perform different tasks. PIC Microcontrollers are relatively cheap and can be bought as pre-built circuits or as kits that can be assembled by the user.

\section{Serial Communication}

The data can be transmitted by the serial communication.

\section{Wireless Water Sentinel platform for monitoring and control of water distribution systems}

Drinking Water Distribution Systems is used to supply drinking water. It supplies water from water sources like reservoirs, or water tanks to industrial, commercial and residential consumers through complex pipe networks. It is necessary to supply adequate and clean water in terms of availability and quality for performing many daily tasks, and disruptions to a water supply through planned maintenance. Urban population growth adds to the demands on the water supply infrastructure. Utilities are faced with increasing costs of installing new pipelines to serve the growing population as well as maintaining and replacing the aging system [10].

In water distribution systems leakage is an important issue as it affects water companies and their consumers worldwide. It has, therefore, attracted a lot of attention of practitioners and researchers as well over the past years. The need to manage leakage in pipe networks of most of the municipalities became more urgent in recent years due to water shortages caused by 
recent draughts, increasing the demand along with environmental, social and political pressures [11].

The water losses consist of real and apparent losses. The real losses consist of water lost through burst pipes, leaking joints, fittings, service pipes, and connections. The apparent losses result from illegal connections, under registration of customers meters, inaccurate meters, stopped meters, vandalized meters, bypassed meters, billing errors, in adequate meter reading policy, and corruption of meter readers. To understand the reasons why, how and where water is being lost, the managers have to carry out an appraisal of the physical characteristics of the network and the current operational practice. The condition of the infrastructure and the renewal or rehabilitation policy is perhaps one of the main reasons for the variation in leakage across the world. Leaks and bursts are the aspects which cannot be avoided easily in water distribution systems. These are reasons for significant water loss. Therefore it is necessary to build a system which has the ability to detect and localize pipe burst and leaks. Water wise platform which focusing on capabilities to detect and localize bursts, identify hotspots, areas at risk of leaks and bursts in the network can be used to solve these problems.

WaterWiSe (Wireless Water Sentinel) is a platform for water distribution systems operators that provides real-time monitoring and decision support tools that can be used to help improve system management and operation. WaterWiSe uses a combination of model-based prediction and data stream analysis as a basis for its decision support tools. The primary data source is a Wireless Sensor Network (WSN) that is deployed on the pipes within the distribution system, providing on-line updates of the hydraulics and water quality. Increase of deployment density, number of parameters and on-line data collection enabled by deploying the WaterWiSe. WSN allows a water utility to have a more detailed picture of the water distribution system across a variety of important applications, such as leak detection, water quality monitoring, on-line hydraulic calibration and others

The WaterWiSe platform consists of three layers as shown in figure 6 :

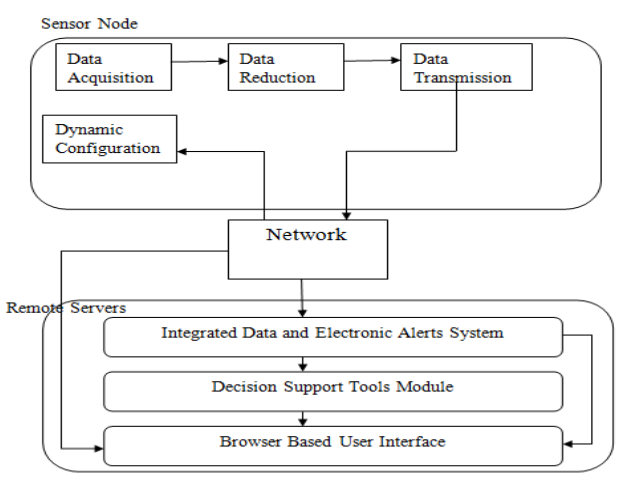

Figure 6 -The relationship between WaterWiSe layers

\subsection{Sensor Node}

Sensor node manages the Wireless Sensor Network (WSN). A Wireless Sensor network are spatially distributed autonomous sensors. These sensors can monitor physical or environmental conditions, such as temperature, sound, pressure, etc. and to cooperatively pass their data through the network to a main location [12].
The sensor nodes are connected to the water distribution pipes via tapping points. These nodes collect real time sensor measurements, log system diagnostic data, and transmit the collected data to the backend server infrastructure. The server archives the data, performs data processing, interfaces with hydraulic modeling tools, and hosts a web portal providing various services for data access and visualization. The sensor node is custom designed for continuously collecting sensor data at $2 \mathrm{KHz}$ sampling rate and transmitting the data in real time over $3 \mathrm{G}$ or Wi-Fi interfaces. It also has the ability to perform local data processing when appropriate.

Wireless Sensor Network is deployed in network, and provides on-line streams of data. These Waterwise nodes can be remotely and dynamically configured. It senses and transmits data in variety of ways. WSN Measures hydraulic and water quality parameters within water distribution network.

\subsection{The Integrated Data and Electronic Alerts System (IDEAS)}

IDEAS is responsible for data stream management, processing and alert notification. On-line data from the WSN is archived as it arrives along with data from other sources such as a utility's SCADA (Supervisory Control and Data Acquisition) system, or operational information such as valve closures and pump schedules. IDEAS has a set of analytics that are applied to data streams in order to detect abnormal events and provide location estimates. Detection of an abnormal event triggers an alert to be sent via e-mail or SMS to subscribed users of WaterWiSe.Integrated Data and Electronic Alerts System collect data from WSN layer and processes that data streams to detect and localize abnormal events like leaks or water contamination events. Burst events are detected from measurements of pressure transients using a combination of wavelet decomposition and time domain statistical analyses [10].

\section{Event detection through wavelet decomposition}

The wavelet event detection technique used in WaterWiSe is based on multi-scale analysis of the pressure signal to detect transients. It has the following steps:

- Apply wavelet de-noising (to remove impulsive noise in pressure stream)

- Compute the wavelet decomposition of de-noised signal

- Identify signal features

- Determine temporal consistency of signal features across wavelet scales

- Classify signal features to determine if event or not

- Focus on transient arrival time

\section{Localization algorithms}

The IDEAS layer in WaterWiSe uses a graph-based search algorithm that incorporates the arrival times of transient detections at the sensor nodes to localize the event

\subsection{The Decision Support Tools Module (DSTM)}

The Decision Support Tools Module layer comprise of decision support tool. It utilizes sensor information stream which is given by IDEAS and model the water system as an arrangement of demand-zones. The calibration process utilizes the latest pressure and flow data information from 
sensor nodes alongside a baseline demand pattern and regular data to evaluate the utilization for every demand zone in the system model.The operation simulation tool can be utilized by engineers with the goal that they can break down the potential effect on the system of an operational events, similar to valve terminations and pipe isolations. Engineers can choose one or more valves to isolate and focus the times for which these valves will be shut. In the wake of finishing, the simulation results are displayed, from which pipes that will have low or reversed flow can be distinguished, additionally areas that will have unusually low or high pressure, and clients that will be isolated by the operation.

Utilizing the demand prediction tool, water utilization can be predicted in advanced for a 24-hour rolling window. Expectations can be demonstrated on an everyday report, with examination to the genuine utilization, over the entire zone or in particular sub-zones. Water age in the framework can be predicted and thought about against the real time water quality estimations being taken in the framework. This serves to recognize areas of high water age that may be of concern. In frameworks where water is pumped to buyers or capacity tanks, WaterWiSe can help decrease cost and energy consumption by improving the pump operation schedule based on electricity tariffs, a pump's productivity and anticipated water utilization in the framework [10].

The general work is coordinated towards three primary objectives: 1) The use of low cost WSN for high data rate, online monitoring of hydraulic parameters within a large urban water distribution system; 2) The advancement of frameworks to empower remote location of leaks and expectation of pipe burst occasions; 3) The incorporated checking of hydraulic and water quality parameters.

The utilizations of this framework incorporate remote location of pipe burst and leak events, constant hydraulic modeling for conveyance arranging through water request expectation, and water contamination checking and mitigation. At present, a suite of statistical and wavelet decomposition techniques to identify pipe burst occasions continuously is currently improvement and assessment. Taking into account the estimation of the entry times of the weight front at different nodes after a pipe burst occasion, the framework can focus the area of the pipe burst. The sensor information has additionally been incorporated with hydraulic models to predict the water request at different interest zones

\subsection{Condition Rating Model for Underground Infrastructure Sustainable Water Mains}

Structural condition of Water distribution system becomes worse as it continues to age. As well as hydraulic capacity and performance of the system get decrease. In this manner, the requirement for review and appraisal of the water framework is expanded to keep up and overhaul this framework, which will spare a considerable measure of time and cash. The artificial approach has been used to monitor the conditions of water flow in the underground system. Condition rating scale with its associated course of actions, is also described in the research

The purpose of the condition rating is to objectively rate or scale the current condition of buried pipes. An ANN (Artificial Neural Network) model is developed to rate or scale the current condition of water mains based on several physical, environmental, and operational factors, which provide the basic terminology and framework for the current model.As shown in the table 2, each variable is represented by one artificial neuron in the ANN input layer eight neurons: type of pipe, age, size diameter, rate of breakage, $C$ factor Hazen-William factor, depth, type of road surface, and type of soil. The current study considers three categories of pipes: asbestos, cast iron, and ductile iron. The type of road surface consists of three categories: asphalt, seal, and unpaved.

Table 2- Description of Factors Included in the ANN Model

\begin{tabular}{|l|l|l|}
\hline Number & Factor & Description of factor \\
\hline 1 & Type of soil & $\begin{array}{l}\text { Clay, sand, silt, crushed } \\
\text { stone, etc. }\end{array}$ \\
\hline 2 & $\begin{array}{l}\text { Type of road } \\
\text { surface }\end{array}$ & Asphalt, seal, or unpaved \\
\hline 3 & Pipe diameter & Internal diameter of pipe \\
\hline 4 & Pipe material & $\begin{array}{l}\text { Type of pipe cast iron, } \\
\text { ductile iron, asbestos }\end{array}$ \\
\hline 5 & Pipe age & Age of laid pipe \\
\hline 6 & Cover & Installation depth of a pipe \\
\hline 7 & $\begin{array}{l}\text { Number of } \\
\text { breaks }\end{array}$ & $\begin{array}{l}\text { Number of pipe } \\
\text { breaks/km/year }\end{array}$ \\
\hline 8 & C factor & Hazen-William coefficient; \\
\hline
\end{tabular}

The output variable includes one neuron: condition rating scale from 0 to 10 . Therefore, the ANN includes only one neuron in the output layer. NEUROSHELL software is used to develop the proposed ANN model. The ANN learning rate is 0.005 , the rate at which the ANN will learn patterns in the training data set, and the number of learning events is 568,400 . The minimum average error in training is $0.00119[13]$.

\subsection{Development of An Intelligent System For Underground Pipeline Assessment, Rehabilitation And Management}

The Intelligent system is the state-of-the-art concept which performs data acquisition, data interpretation and utilization of the data for intelligent renewal of pipeline infrastructure systems. It can be used by expert municipal engineer in performing condition assessments and identification of suitable rehabilitation process and some maintenance strategies. It uses different approaches to condition data acquisition and also gives variety of techniques for processing data and signals [14].

Different types of NDT (Non Destructive testing) methods can be used for the inspection of defects. NDT is important in guaranteeing safe operation. Also it provides properties like quality control and evaluating pipe life. The defects may be pipe cracks or inclusions in welds or variations in structural properties that may cause loss of strength or sometimes failure in service. NDT is used for in service inspection and for condition monitoring. Also NDT is used for measurement of components and physical properties such as hardness and internal stress. Another method is CCTV inspection where defects are identified from images .Most of the municipal pipeline systems are inspected using this method [14].The Integrated pipeline management system is used for intelligent renewal of municipal infrastructure systems. This system could automate in real time much of the pipeline data acquisition, interpretation and evaluation process and capture the experience and judgment of expert municipal engineers in performing condition assessments and identification of appropriate rehabilitation and maintenance strategies. The IPMS combines automated condition assessments and predictions of future conditions will help asset managers and 
engineers to make consistent and cost effective decision related to preservation of municipal infrastructure systems.

\subsection{ISO Standards}

Table 3 - ISO Standards for Water Distribution System

\begin{tabular}{|l|l|l|}
\hline Category & Standard ID & Description \\
\hline Water quality & (ISO/TC 147) & $\begin{array}{l}\text { water quality standards provide a common } \\
\text { terminology, water sampling methods and reporting } \\
\text { and monitoring guidance to check presence of } \\
\text { bacteria, purity and other characteristics }\end{array}$ \\
\hline Water footprint & (ISO/TC 207/SC 5 & $\begin{array}{l}\text { The standard will help organizations harmonize } \\
\text { reporting, setting an international benchmark for } \\
\text { water use. }\end{array}$ \\
\hline Hydrometry & (ISO/TC 113) & $\begin{array}{l}\text { They enable reliable and accurate measurements, and } \\
\text { facilitate self-sufficiency in meeting future water } \\
\text { needs. }\end{array}$ \\
\hline Piping \& valves & $\begin{array}{l}\text { ISO standards for performance, materials, test } \\
\text { methods, data interpretation and reporting (ISO/TC } \\
\text { 23/ SC 18) promote a more efficient irrigation, } \\
\text { easing the strain on water resources }\end{array}$ \\
\hline & $\begin{array}{l}\text { pipes (ISO/TC 138) cast iron pipes } \\
\text { (ISO/TC 5/SC 2) } \\
\text { valves (ISO/TC 153) }\end{array}$ & $\begin{array}{l}\text { Improve quality of life, by ensuring water supply } \\
\text { systems are reliable and enabling efficient access to } \\
\text { this resource }\end{array}$ \\
\hline
\end{tabular}

The ISO Standards related to Water Distribution System is given in Table 3.

\section{CONCLUSION}

Underground maintenance is challenging problem. Different system are proposed for the maintenance out of which some systems like manhole identification, underground drainage maintenance system and water distribution system are explained. This paper proposes different methods for monitoring and managing underground drainage system with different approaches. It explains various applications like Underground Drainage and Manhole Monitoring System, manhole identification and also for water distribution and monitoring system. In this study, the design of specialpurpose RFID tags, affixed with a metal surface, longdistance reading, and reduces the interference characteristics of water, known as Ground Tag. Also described WaterWiSe an integrated platform combining a real-time wireless sensor network with intelligent analytics and modeling tools to better aid water distribution system operation and management with ANN model which is robust and can be used to predict the condition rating of water mains and ANN model is robust and can be used to predict the condition rating of water mains.

\section{ACKNOWLEDGEMENT}

We are thankful to Dr. S.C.Mehrotra for his constant support and Guidance. We would also like to express our thanks to the department of Computer Science \&IT for providing facilities needed to carry out this study.

\section{REFERENCES}

[1] Allen Y. Chang, Chang-Sung Yu,Sheng-Chi Lin,Yin-Yih Chang, pei-Chi Ho," Search, Identification and Positioning of the Underground Manhole with RFID”ISBN: 978-0-7695-3769-6 ,pp: 1899-1903
[2] http://www.thomasathomas.com/Metal_detectors_work.h tm

[3] MandeepKaur, ManjeetSandhu, Neeraj Mohan and Parvinder S. Sandhu " RFID Technology Principles, Advantages, Limitations\& Its Applications" International Journal of Computer and Electrical Engineering, Vol.3, No.1, February, 2011 1793-8163

[4] Christoph Jechlitschek, "A survey paper on Radio Frequency Identification (RFID) Trends"Available online at: http://www1.cse.wustl.edu/ jain/cse57406/index.html

[5] Joe Purtell "Mapping the Underground infrastructure: Leveraging GPS Technology to locate and identify problems" North American Society for Trenchless Technology (NASTT) No-Dig Show 2010 Chicago, Illinois May 2-7, 2010

[6] PETER H. DANA “Global Positioning System (GPS) Time Dissemination for Real-Time Applications"Available online at: http://www.pdana.com/phdwww_files/rtgps.pdf

[7] Abdul-LateefBalogun, Abdul-NasirMatori, Dano Umar Lawal, "Geovisualization of Sub-surface Pipelines: A 3D Approach" Published by Canadian Center of Science and Education, Modern Applied Science Vol. 5, No. 4; August 2011.

[8] Gerhard Schall, Dieter Schmalstieg, Sebastian Junghanns, "VIDENTE - 3D Visualization Of Underground"Infrastructure Using Handheld Augmented 
Reality”Availableonlineat:http://www.icg.tugraz.at/Mem bers/schall/geohydo.pdf

[9] Muragesh SK and Santhosha Rao "Automated Internet of Things for Underground Drainage and Manhole Monitoring System for Metropolitan Cities" International Journal of Information \& Computation Technology. ISSN 0974-2239 Volume4, Number12 (2014), pp.12111220 at http://www.Irphouse.com

[10] Whittle, A. J., M. Allen, A. Preis, and M. Iqbal. "Sensor Networks for Monitoring and Control of Water Distribution Systems." 6th International Conference on Structural Health Monitoring of Intelligent Infrastructure (SHMII 2013), Hong Kong, December 9-11, 2013

[11] R. R. Dighade, M. S. Kadu, A.M.Pande "Challenges in Water Loss Management of Water Distribution Systems in Developing Countries." International Journal of Innovative Research in Science, Engineering and Technology (An ISO 3297: 2007 Certified Organization) Vol. 3, Issue 6, June 2014
[12] https://en.wikipedia.org/wiki/Wireless_sensor_network

[13] Hassan Al-Barqawi and TarekZayed "Condition Rating Model for Underground Infrastructure Sustainable Water Mains" Journal of Performance of Constructed Facilities, JOURNAL OF PERFORMANCE OF CONSTRUCTED FACILITIES @ A ASCE / MAY 2006Vol. 20, No. 2, ISSN 0887-3828/2006/2-126-135

[14] Sunil K Sinha, "Development of an Intelligent system for underground pipeline assessment, rehabilitation and management"Availableonline http://www.researchgate.net/publication/ http://www.researchgate.net/publication/228963212_DE VELOPMENT_OF_AN_INTELLIGENT_SYSTEM_FO R_UNDERGROUND_PIPELINE_ASSESSMENT_RE HABILITATION_AND_MANAGEMENT 